\title{
Thermomechanical behavior of micron scale solder joints under dynamic loads
}

\author{
Y. Zhao ${ }^{\text {a }}$, C. Basaran ${ }^{\text {a,* }}$, A. Cartwright ${ }^{\text {a }}$, T. Dishongh ${ }^{\text {b }}$ \\ ${ }^{a}$ SUNY at Buffalo, Electronic Packaging Laboratory, School of Engineering and Applied Sciences, 212 Ketter Hall, North Campus, \\ Amherst, NY 14260-4300, USA \\ b Intel Corporation, Hillsboro, OR, USA \\ Received 21 July 1999
}

\begin{abstract}
Recent trends in reliability and fatigue life analysis of electronic devices have involved developing structural integrity models for predicting the operating lifetime under vibratory and thermal environmental exposure. Solder joint reliability is the most critical issue for the structural integrity of surface mounted electronics. Extensive research has been done on thermal behavior of solder joints, however, dynamic loading effects to solder joint fatigue life have not been thoroughly investigated. The physics of solder joint failure under vibration is still not very clear. This paper presents a test program which was performed to study inelastic behavior of solder joints of BGA packages. A concurrent loading unit is used which consists of a thermal environmental chamber and an electrodynamic shaker. Laser Moiré Interferometry was used to measure the whole deformation field of the prepared specimen surface. The corresponding inelastic strain field is then calculated. It is found that at elevated temperature, vibration and shock can cause the accumulation of inelastic strains and damage in solder joints. In this paper, contrary to the popular belief that all vibration-induced strains are elastic, it is shown that vibration can cause significant inelastic strains. (C) 2000 Elsevier Science Ltd. All rights reserved.
\end{abstract}

Keywords: Solder joint; Electronic packaging; Vibration; Moiré interferometry

\section{Introduction}

Thermal behavior of electronic packaging has received extensive attention and has been studied by many researchers. Due to its application purposes, electronic devices are manufactured as multilayered structures with very different mechanical as well as electrical properties pertaining to each layer mostly designed to meet the re-

\footnotetext{
${ }^{*}$ Corresponding author. Tel.: +1-716-645-2114/2429; fax: +1716-645-3733.

E-mail address: cjb@eng.buffalo.edu (C. Basaran).
}

quirements of electronic service. Fast developing technologies bring in computer chips with very high power density for better performance, which makes the thermal expansion mismatch problem even severe. It has been generally recognized that thermal loading is one of the major causes to the failure of electronic devices during its service life. Especially the solder joints that act as mechanical support as well as electrical interconnection, are very important parts for the integrity of electronic devices.

However, a number of categories of electronic devices have to endure even severe working 
environments that involve not only thermal but also dynamic loading conditions. The US Air Force estimates that vibration and shock cause $20 \%$ of the mechanical failures in airborne electronics. Empirical fatigue life prediction of components, component leads and joints has been determined based on the dynamic displacement of printed circuit board (PCB) (Marstein, 1987). However, the nonlinear stress-strain behavior of solder joint under vibration is still not clear. Dynamic loading effect to solder joint fatigue life has not been systematically studied. And the role of vibration in the life of solder joint has not been recognized sufficiently.

According to the literature survey, vibration fatigue analyses which have been done by now are mainly model testing, mode analysis, and cyclic failure investigation. Only very few existing fatigue models are based on stress or strain analysis. Steinberg (1988) developed an empirical relation to estimate the fatigue life of components mounted on a PCB based on testing and experience. Lau et al. (1990) studied solder joint reliability under shock and vibration. They conducted in-plane random vibration testing, in-plane shock testing, out-of-plane vibration testing, and out-of-plane shock testing. Their testing was limited to determine the failure status after certain cycles of dynamic loading. Wong et al. (1991) reported experimental modal analysis and dynamic response prediction of PCBs under out-of-plane vibration. Ham and Lee (1996) also conducted reliability testing of electronic packaging under vibration. An experimental method was developed to measure the changes in electrical resistance in the lead which is used to indicate a fatigue life. They discussed a relationship between the loading forces and the high-cycle fatigue life for the lead part of spider gullwing type surface-mounted component. Liguore and Followell (1995) also reported a test program to obtain structural fatigue data for SMT solder joints exposed to an out-of-plane random vibration environment. Dynamic response characteristics of the PCBs was studied, and empirical fatigue model for components, component leads and solder joints was discussed in their paper. Sidharth and Barker (1995) reported vibration fatigue life estimation of corner

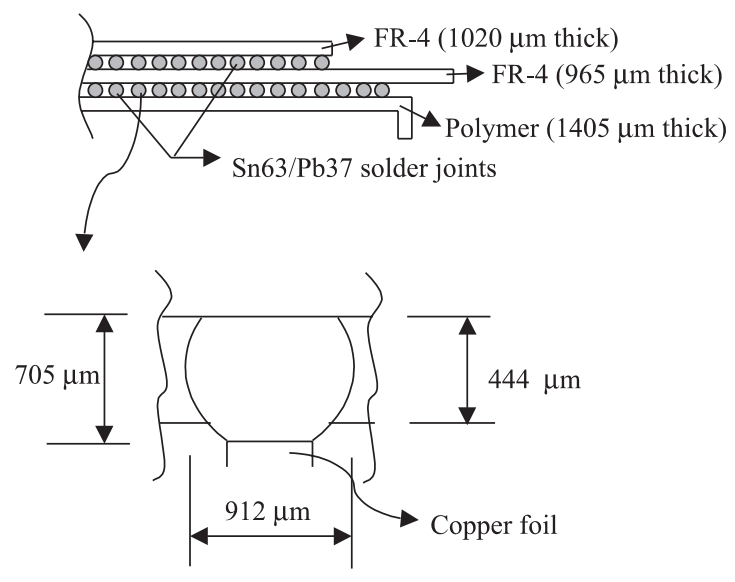

Fig. 1. Cross-section of the BGA specimen.

leads of peripheral leaded components using linear elastic finite element procedure.

This paper presents the results of a series of laboratory tests dedicated to the investigation of dynamic behavior of $63 \mathrm{Sn} / 37 \mathrm{~Pb}$ eutectic solder joints in a new generation high performance CPU chip with ball grid array (BGA) configuration. The purpose of this project is to study the nonlinear inelastic response of the solder joints under vibration at certain temperature, and the role of dynamic loading to the fatigue life of the solder joints.

The tested BGA package has the structure and material composition shown in Fig. 1. In the shock tests, continued shock was applied at room temperature and at temperature range ramping from $20^{\circ} \mathrm{C}$ to $130^{\circ} \mathrm{C}$. In harmonic vibration tests, sinewave vibrations were conducted at $20^{\circ} \mathrm{C}$ and $100^{\circ} \mathrm{C}$. The plastic deformation in each solder joint after each shock and vibration test was measured by laser Moiré Interferometry.

\section{Experimental procedures}

There are two relatively independent parts in the entire testing procedure. One is the loading part, and the other is the optical measurement part. For the first part, an environmental thermal chamber and an electrodynamic shaker are used simultaneously. For the second part a laser Moiré 
Interferometry device was designed and manufactured for deformation measurement at the resolution of half of the light wavelength (submicron).

\section{Concurrent loading unit}

A high capacity Super AGREE environmental chamber by Thermotron (SA-36-CHV-30-30) is used to control the environmental temperature, which is shown in Fig. 2. It is capable to maintain the temperature within the range of $\pm 1^{\circ} \mathrm{C}$, and its fastest ramping rate is $30^{\circ} \mathrm{C} / \mathrm{min}$.

The electrodynamic shaker system is $\mathrm{UN}$ HOLTZ-DICKIE model S092HS, shown in Fig. 3. It consists of a power amplifier, electrodynamic shaker, DC field supply, and remote-cooling blower. The shaker armature incorporate a multiribbed table for maximum stiffness and minimum weight, and is ideal for application requiring high $\mathrm{g}$ (up to $360 \mathrm{~g}$ shock and $100 \mathrm{~g}$ sine) level testing involved in this project. A personal computer is specifically equipped for the shaker system for

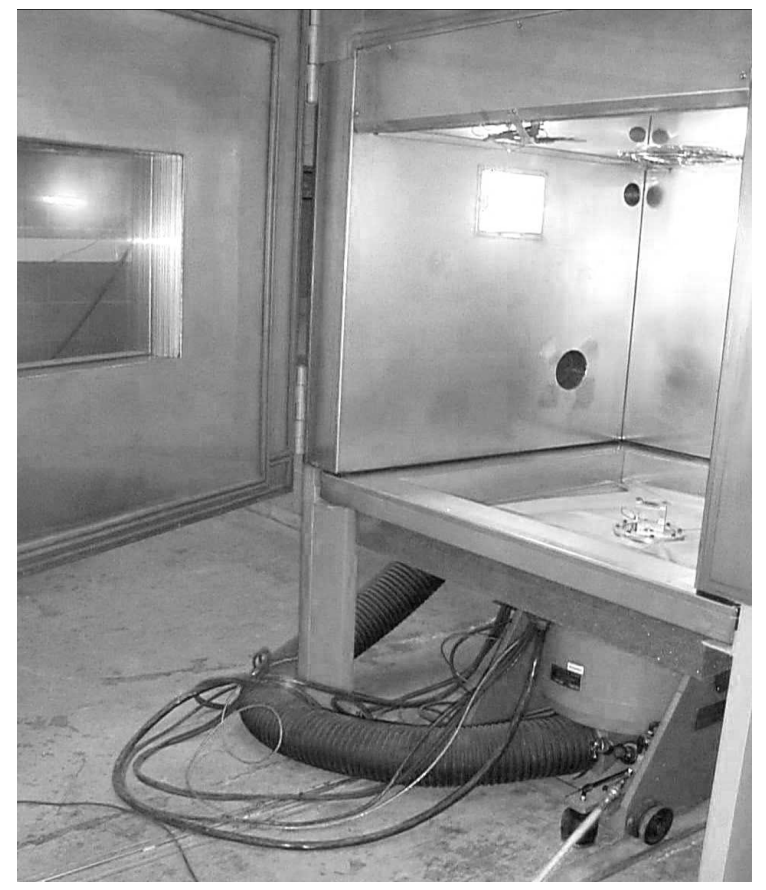

Fig. 2. Concurrent thermal-dynamic loading unit.

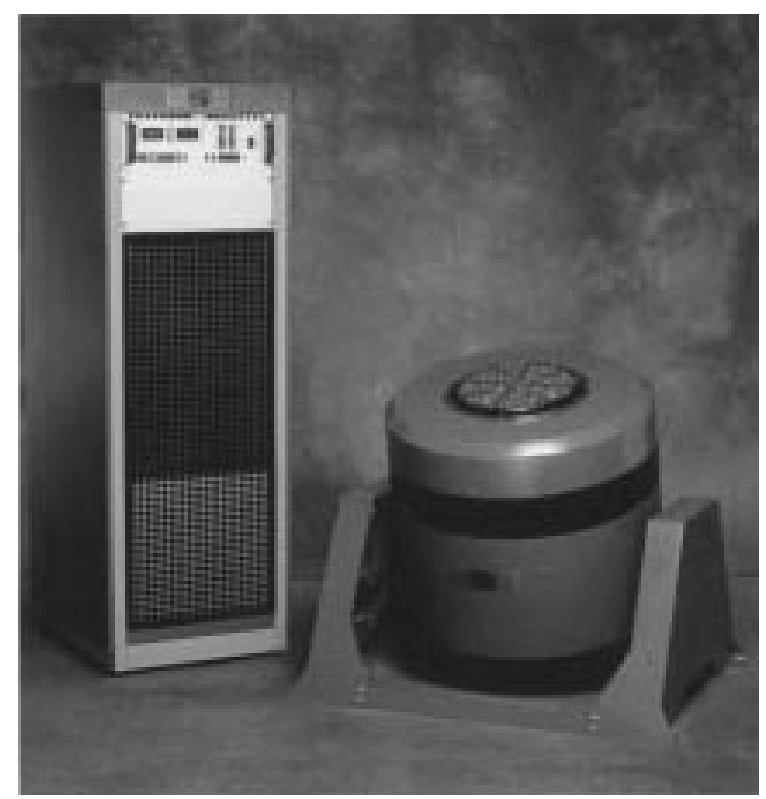

MODEL SA15-S452-PB

Fig. 3. Electrodynamic shaker.

function generating, test control, test monitoring, and data acquisition, and form a closed loop together with the power amplifier, shaker, accelerometer and charge amplifier. It is capable of performing random vibration, sinusoidal vibration, and shock.

To combine the shaker and the chamber, the shaker is inserted underneath the chamber and the slip table of the chamber is replaced by a special flexible thermal barrier. An aluminum round plate with the same configuration as the shaker armature table is made to hold the specimen fixture inside the chamber. The plate is connected to the armature table through the thermal barrier. Fig. 2 shows the concurrent loading unit, and Fig. 4 shows the special specimen fixture for the concurrent testing.

\section{Moiré Interferometry}

The Moiré Interferometry (MI) and the imaging systems used for submicron displacement measurement have been described in detail in Zhao 


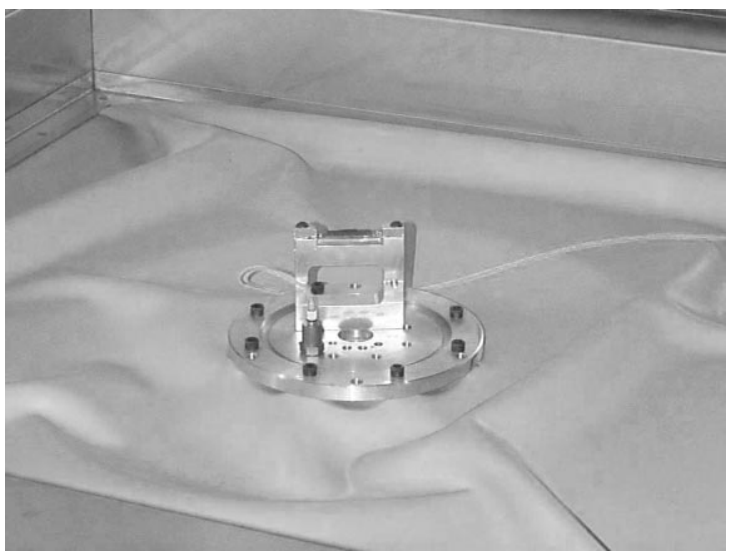

Fig. 4. Specimen fixture for the concurrent test.

et al. (1999). The major advantage of MI is its high sensitivity, high resolution, and the whole field view of deformation distribution of the specimen surface. Briefly, the optical diffraction grating is replicated on the specimen surface. The specimen grating diffracts the incident two coherent beams with certain incident angle, and in the direction normal to the specimen surface, two strong diffracted beams are obtained. When the specimen surface deforms, the optical diffraction grating deforms with the specimen, and the diffracted two beams in the normal direction generate feature interferometry pattern that represents the in-plane displacement distribution. The one-dimensional setup of MI is shown in Fig. 5. This scheme applies to both horizontal and vertical direction, so that deformation in the two perpendicular directions can be obtained. The feature fringe pattern generated by the vertical two beams represents the vertical deformation field, and the fringe pattern generated by the horizontal two beams represents the horizontal deformation field. Fig. 6 shows the optical table for real MI designed for this project.

The fringe pattern can be related to in-plane deformation quantitatively as given by Post et al. (1994):

$$
\begin{aligned}
& U=\frac{N_{x}}{f}, \\
& V=\frac{N_{y}}{f},
\end{aligned}
$$

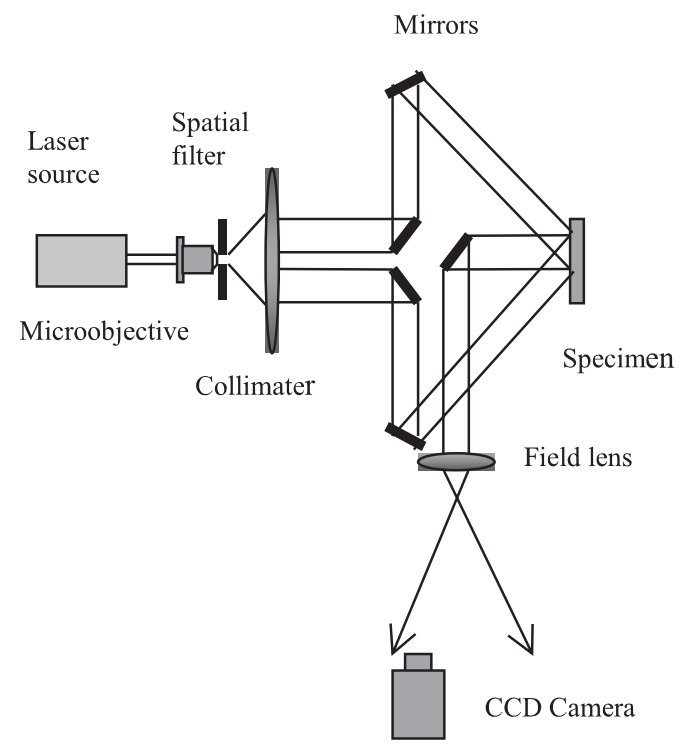

Fig. 5. Optical setup for Moiré Interferometry.

where, $U$ is the displacement in $x$ direction; $V$ is the displacement in $y$ direction; $f=2 f_{\mathrm{s}}, f_{\mathrm{s}}$ is the frequency of specimen diffraction grating, in this study, $f_{\mathrm{s}}=1200$ lines $/ \mathrm{mm} ; N_{x}$ is the horizontal fringe order, and $N_{y}$ is the vertical fringe order. Thus, each fringe represents $1 / f=0.417 \mu \mathrm{m}$ in this study.

Once the displacement data are available the plastic strains are computed by differentiation of the displacement distributions with respect to the two basic directions: horizontal $(x)$ and vertical (y). The strains are given by

$$
\begin{aligned}
& \varepsilon_{x}=\frac{\partial U}{\partial x}=\frac{1}{f}\left[\frac{\partial N_{x}}{\partial x}\right], \\
& \varepsilon_{y}=\frac{\partial V}{\partial y}=\frac{1}{f}\left[\frac{\partial N_{y}}{\partial y}\right], \\
& \gamma_{x y}=\frac{\partial U}{\partial y}+\frac{\partial V}{\partial x}=\frac{1}{f}\left[\frac{\partial N_{x}}{\partial y}+\frac{\partial N_{y}}{\partial x}\right] .
\end{aligned}
$$

\section{Specimen and fixture}

The specimen preparation follows the similar steps as described in Zhao et al. (1999). The specimen was cut by a high precision diamond 


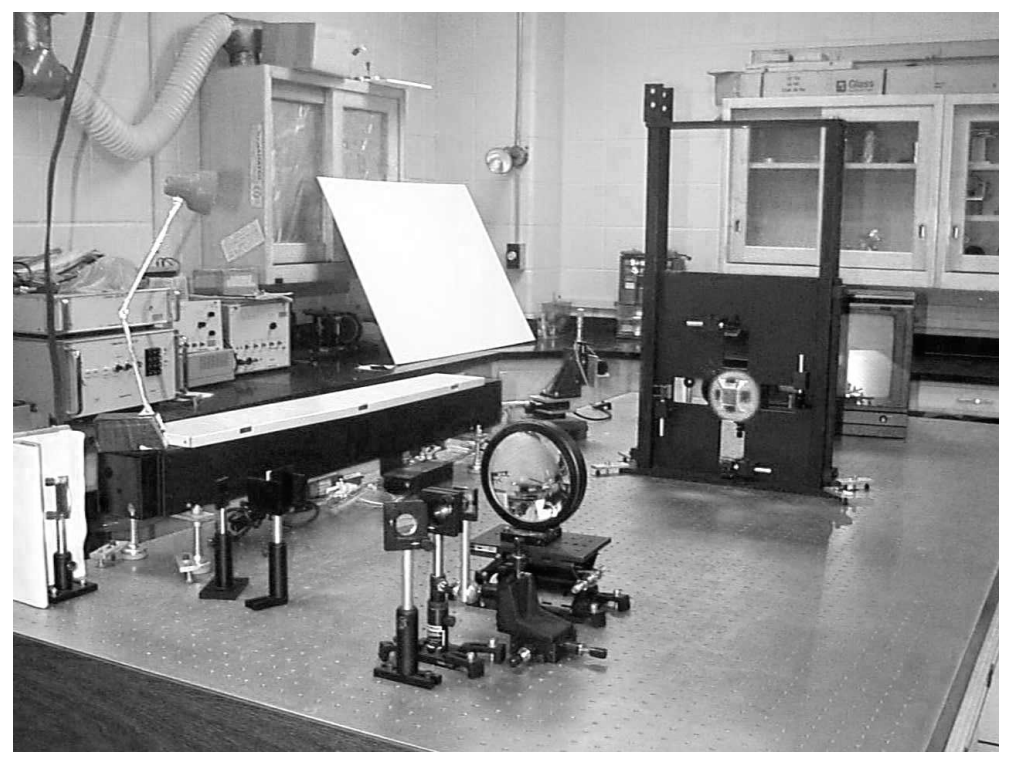

Fig. 6. Optical table for Moiré Interferometry.

wheel saw right through the center of the solder joints of interest to expose the two rows of solder ball joints. There are totally 30 joints in the bottom row, and 24 joints in the upper row. The exposed cross-section was then polished flat, cleaned and dried thoroughly before a thin layer of epoxy was applied on the cut surface to transfer the diffraction grating pattern to the specimen surface.

A special fixture is designed to hold the specimen tightly at two ends of the middle FR-4 layer. This fixture is then mounted on the shaker armature table. The boundary condition and the loading direction are shown in Fig. 7. The acceleration for all the tests is applied in-plane. The estimated natural frequency of the chip specimen under this configuration is well above $1000 \mathrm{~Hz}$ (Lau et al., 1990; Chandaroy, 1998; Basaran and Chandaroy, 1999a,b).

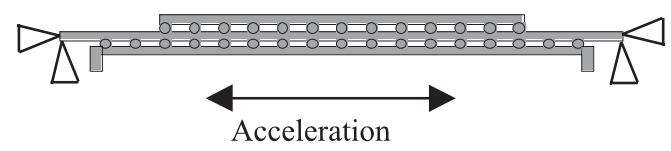

Fig. 7. Boundary condition and dynamic loading direction.

\section{Test results and discussion}

Both shock and harmonic sine vibration were conducted in this project.

\subsection{Results of shock testing}

Two sets of testing were done to examine the dynamic response of BGA solder joints. In the first set of test, shock pulses were continuously applied at room temperature $20^{\circ} \mathrm{C}$ for $5 \mathrm{~min}$. In the other set of tests, shock pulses were applied with concurrent temperature ramping from $20^{\circ} \mathrm{C}$ to $130^{\circ} \mathrm{C}$ for $5 \mathrm{~min}$, and then the specimen was air cooled to room temperature. The same type of shock pulses are applied continuously with peak acceleration $10 \mathrm{~g}$, shock duration $11 \mathrm{~ms}$, total duration $97 \mathrm{~s}$, and delay $103 \mathrm{~ms}$. The loading period is $5 \mathrm{~min}$.

The results of room temperature tests are shown in Fig. 8(a)-(d). Since the specimen is tightly fixed at two ends for the purpose of testing, the initial deformation field is not nulled at the area close to the end. The initial field is subtracted from the final deformation field, therefor the results should not be affected by the initial field 
(a)

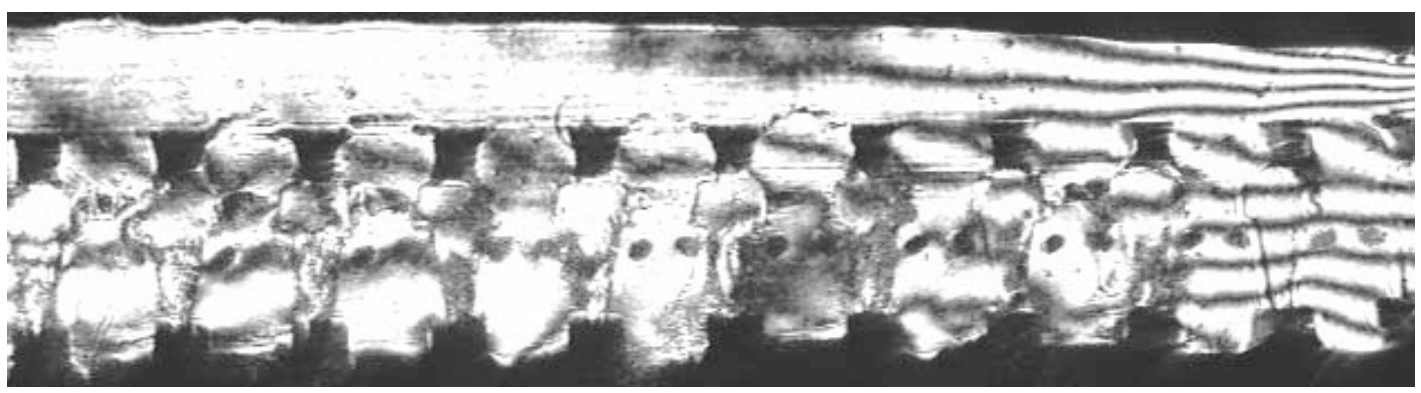

(b)

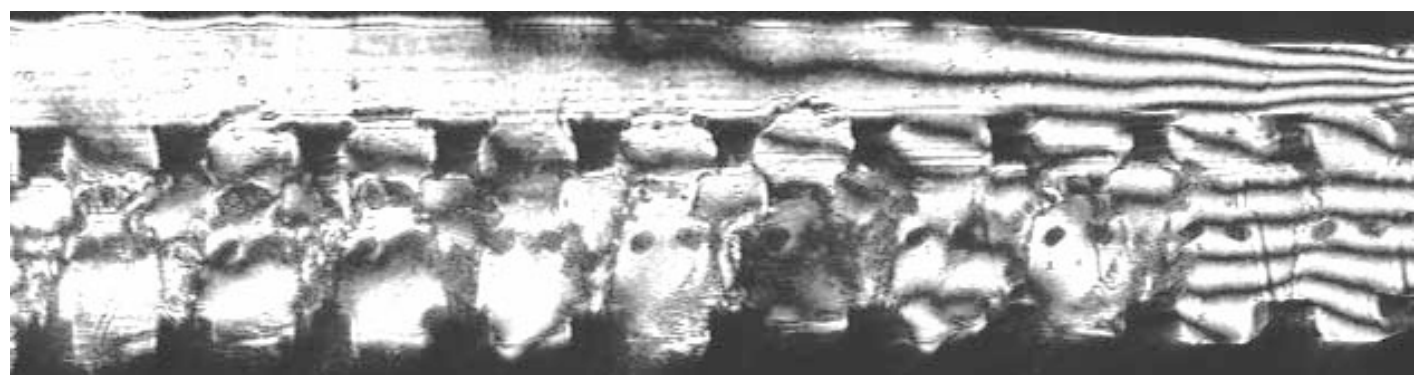

(c)

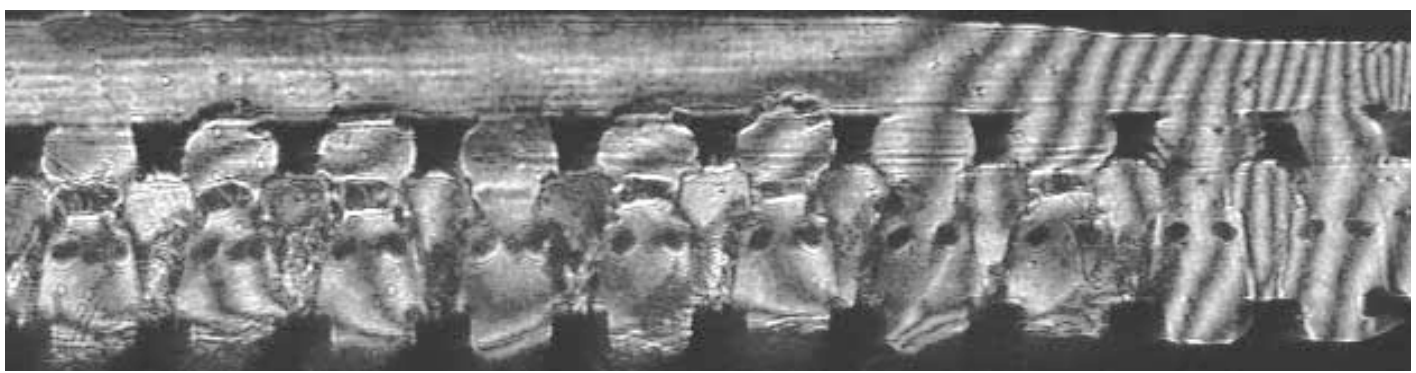

(d)

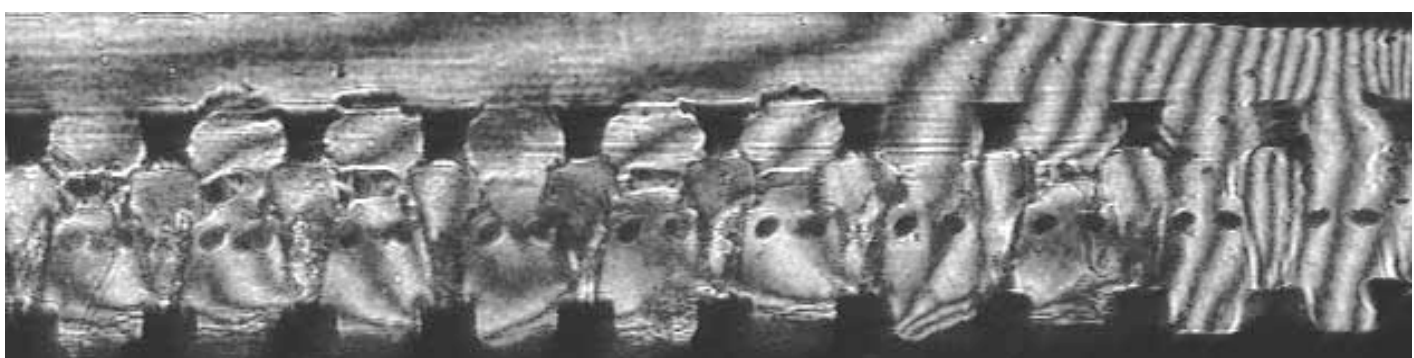

Fig. 8. (a) Initial $U$-field before shock testing, (b) $U$-field after 5 min shock at room temperature, (c) initial $V$-field before shock testing and (d) $V$-field after 5 min shock at room temperature.

which has trivial strains. The measured deformation fields after 5 min room temperature continuous shock testing are given in Fig. 8(c) and (d). These figures show that little change has occurred during the testing which means little inelastic de- formation happened. Obviously, the dynamic response of the solder joints at room temperature in the shock testing is elastic.

The results in the second set of tests are given in Fig. 9(a)-(d). The bottom row of solder joints 
(a)

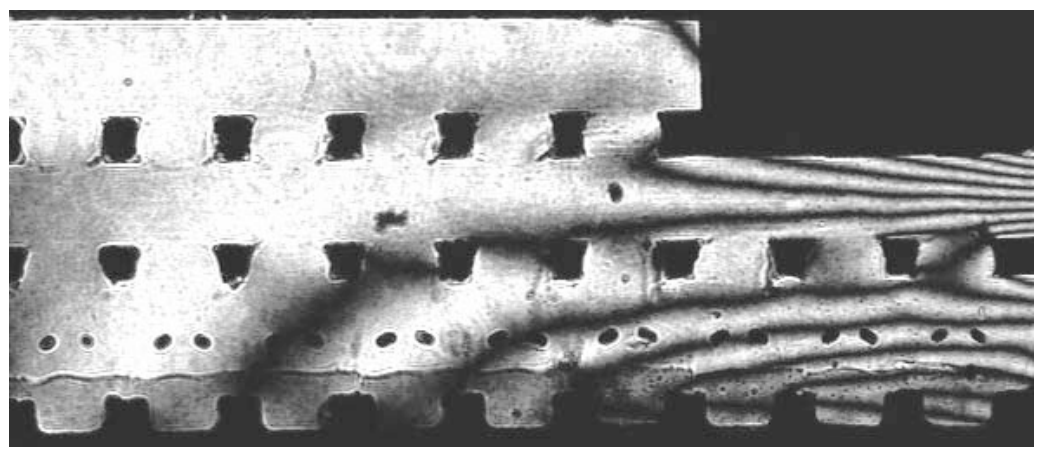

(b)

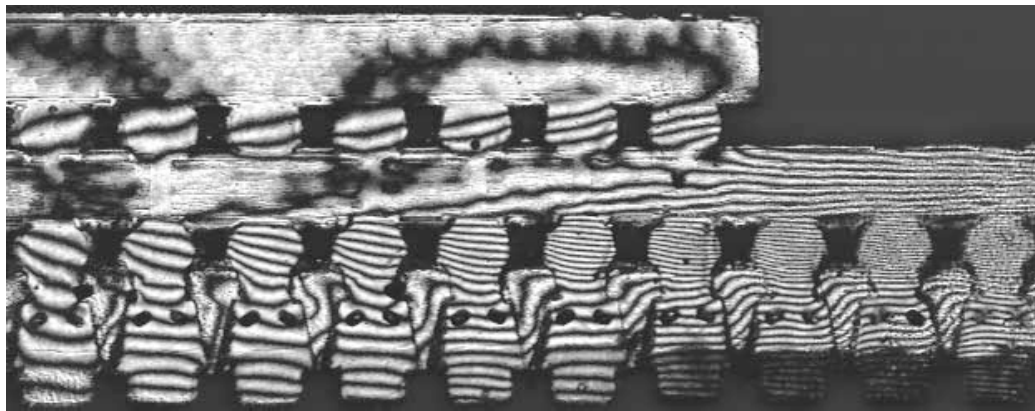

(c)

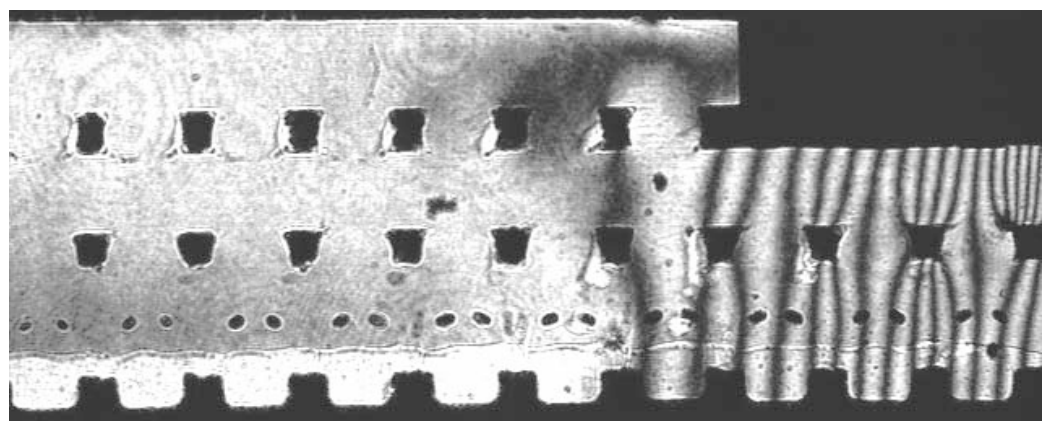

(d)

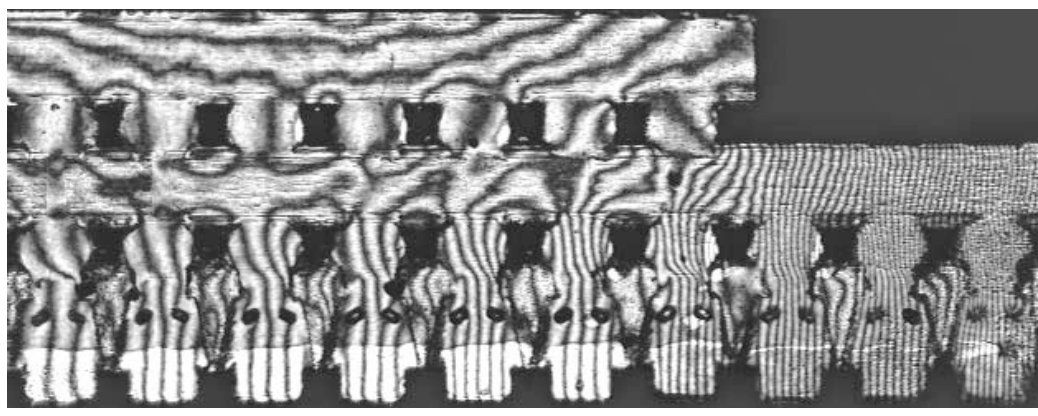

Fig. 9. (a) Initial $U$-field before concurrent thermal and shock testing, (b) $U$-field after concurrent thermal and shock testing, (c) initial $V$-field before concurrent thermal and shock testing and (d) $V$-field after concurrent thermal and shock testing. 
developed significant amount of plastic deformations. Since the bottom row is between the FR-4 layer and the polymer layer, whose coefficients of thermal expansion (CTE) are very different, the thermal effect is very large, and one cannot tell the dynamic effect by now. However, the first row of solders seem to show some dynamic effect. This row of solders are between two identical material layers-FR4, their CTE's are practically the same, whereas their fringe pattern shows significant amount of plastic deformation.

\subsection{Results of harmonic vibration testing}

Also two sets of tests were done to examine the vibration response and the effect of nonlinear response to solder joint fatigue life under harmonic vibration. One set of test was conducted at temperature $20^{\circ} \mathrm{C}$ (which is 0.64 of the melting temperature), and the other tests are conducted at $100^{\circ} \mathrm{C}$ (which is 0.82 of the melting temperature). Each test lasted $42 \mathrm{~min}$. Different frequency values were applied during each set of tests. The applied vibration is of sine wave with peak acceleration of $30 \mathrm{~g}$ in all cases.

\section{Room temperature $\left(20^{\circ} \mathrm{C}\right)$ testing}

In the first set of tests, harmonic sine wave vibrations were applied with frequencies of 2000 , 500 , and $50 \mathrm{~Hz}$ in sequence. The deformation responses indicate that the solder joints in this BGA package behave elastically under vibrations at room temperature.

The MI fringe patters that represent the deformation fields of the first set of tests are shown in Fig. 10(a)-(f). It can be seen that the fringe patterns do not change from the initial fields. The slight differences of the fringe pattern at solder balls are in the error range of MI.

\section{Elevated temperature $\left(100^{\circ} \mathrm{C}\right)$ testing}

Since most semiconductor devices experience heat dissipation during service, studying the effect of vibrations at elevated temperatures is more re- alistic. For the second set of tests, the specimen was heated to $100^{\circ} \mathrm{C}$ and then was subjected to sine wave vibration at the same temperature. Since the specimen is a multilayered structure, and the two ends of the middle board were fixed, heating process introduces thermal stresses and thermal strains. Thermal strains must be subtracted in order to study the vibration-induced deformation. Therefore, the specimen was first heated from $20^{\circ} \mathrm{C}$ to $100^{\circ} \mathrm{C}$ in $5 \mathrm{~min}$, and then was hold at $100^{\circ} \mathrm{C}$ for another $6 \mathrm{~min}$ to allow full relaxation of thermal stresses. It was then air cooled to room temperature for measurement of the initial deformation fields. Therefore, the initial fields actually recorded the plastic deformation caused by heating. Thermal strains were subtracted from elevated temperature vibration test strains to get the vibration induced plastic deformation.

The specimen was then put back to $100^{\circ} \mathrm{C}$ for further testing. 50, 500, 1000 and $700 \mathrm{~Hz}$ frequencies were applied in sequence. And the deformation fringe patterns for each test are shown in Fig. 11(a)-(j). It is obvious, that the fringe patterns change, and deformation became larger as the fringe patterns become denser. Fig. 12 shows the calculated net shear strain induced in each vibration test at $100^{\circ} \mathrm{C}$ at different frequencies. It seems that beyond $1000 \mathrm{~Hz}$, the solder joints subject to vibration behave elastically. However, at lower frequencies, significant plastic strain is developed under vibration. Specifically, smaller frequencies cause larger plastic deformation as shown in Fig. 12. However, the lower frequency limit of $700 \mathrm{~Hz}$ needs to be further explored. It should be pointed out that $700 \mathrm{~Hz}$ is very close to $750 \mathrm{~Hz}$ reported by Basaran and Chasaroy (1998) for the boundary between elastic and plastic behavior. In Fig. 12 solder joint number is in the increasing order from the most side one towards the center ones. In such laminated structures, outer solder joints experience larger shear stress and strain than the center parts (Basaran and Zhao, 1999). Lau and Rice (1985) have shown that the modulus of elasticity increases with frequency and decreases with increased temperature. At higher temperature, solder material also softens, and yield point is much lower than that at room temperature. Therefore with the same 
(a)

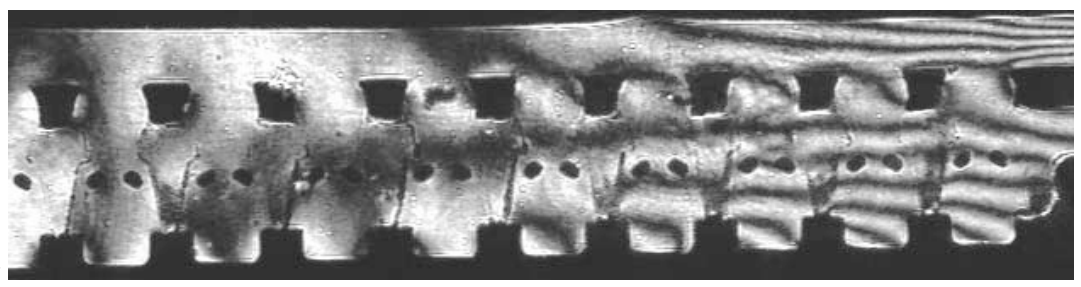

(b)

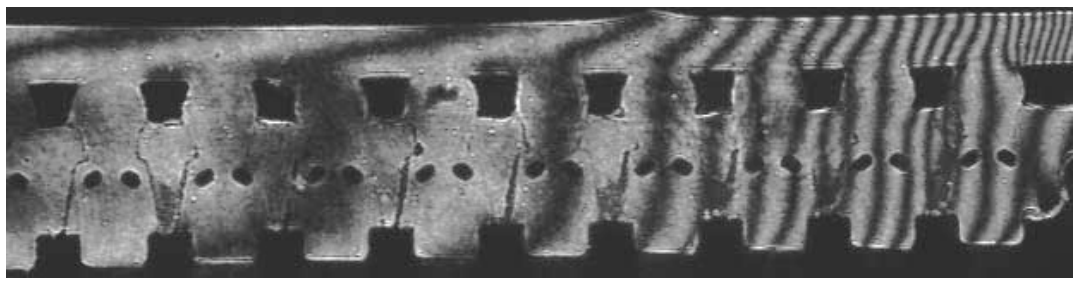

(c)

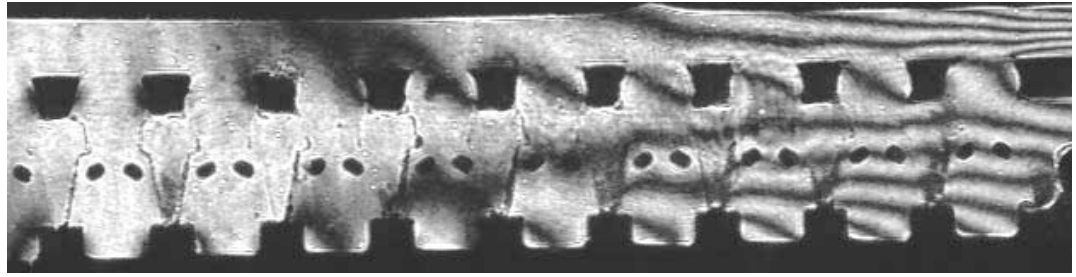

(d)

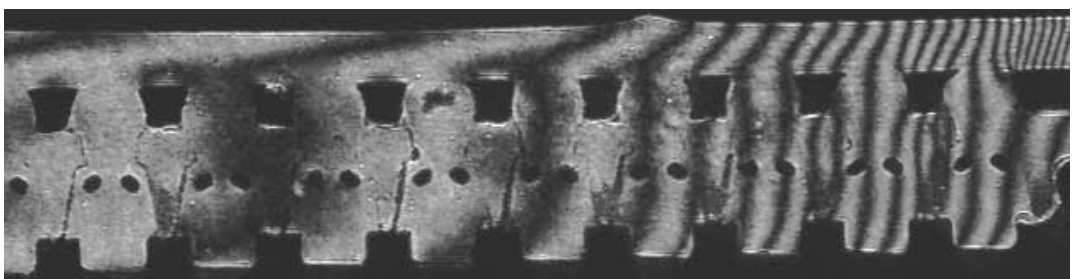

(e)

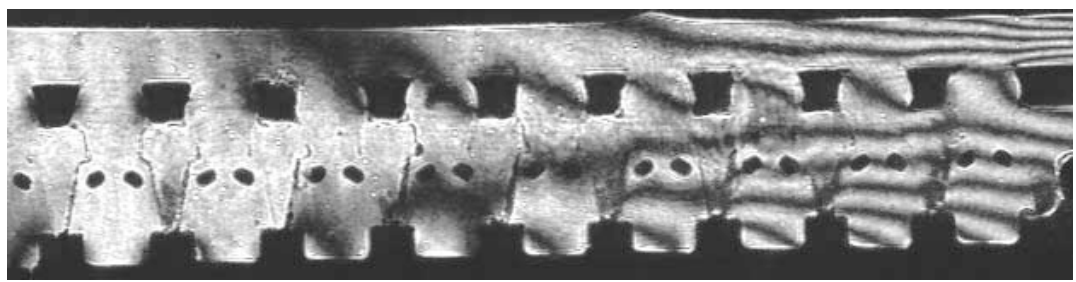

(f)

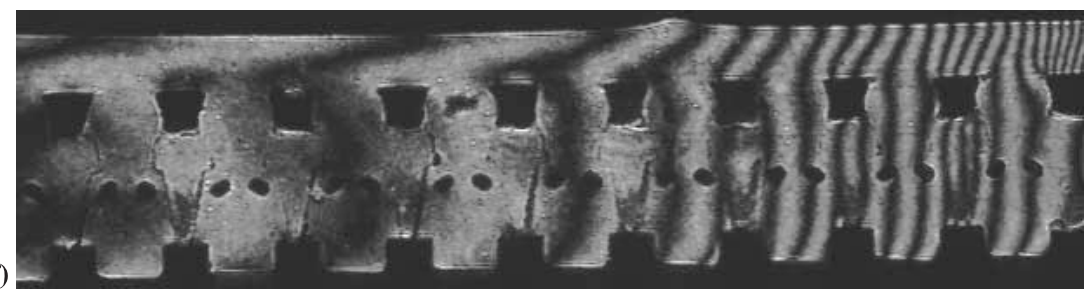

Fig. 10. (a) $U$-field after $42 \mathrm{~min} 2000 \mathrm{~Hz}$ dynamic cycling at $20^{\circ} \mathrm{C}$, (b) $V$-field after $42 \mathrm{~min} 2000 \mathrm{~Hz}$ dynamic cycling at $20^{\circ} \mathrm{C}$, (c) $U$-field after $42 \mathrm{~min} 500 \mathrm{~Hz}$ dynamic cycling at $20^{\circ} \mathrm{C}$, (d) $V$-field after $42 \mathrm{~min} 500 \mathrm{~Hz}$ dynamic cycling at $20^{\circ} \mathrm{C}$, (e) $U$-field after $42 \mathrm{~min} 50 \mathrm{~Hz}$ dynamic cycling at $20^{\circ} \mathrm{C}$ and (f) $V$-field after $42 \mathrm{~min} 50 \mathrm{~Hz}$ dynamic cycling at $20^{\circ} \mathrm{C}$. 
(a)

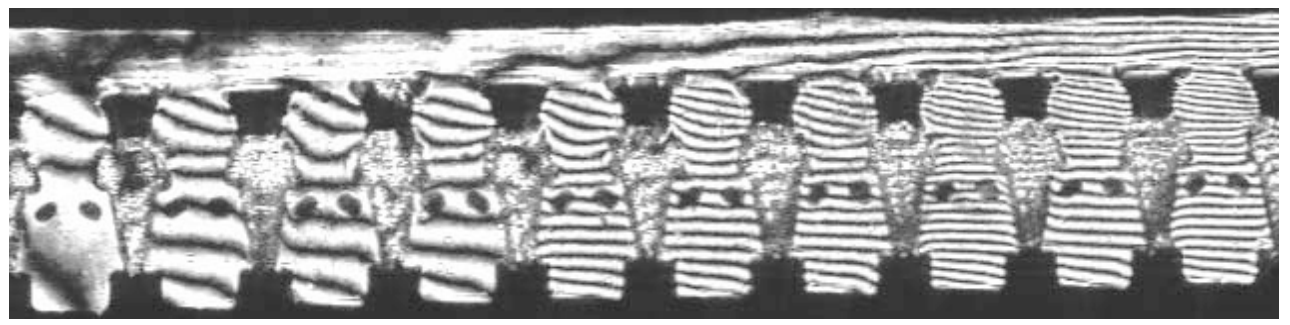

(b)

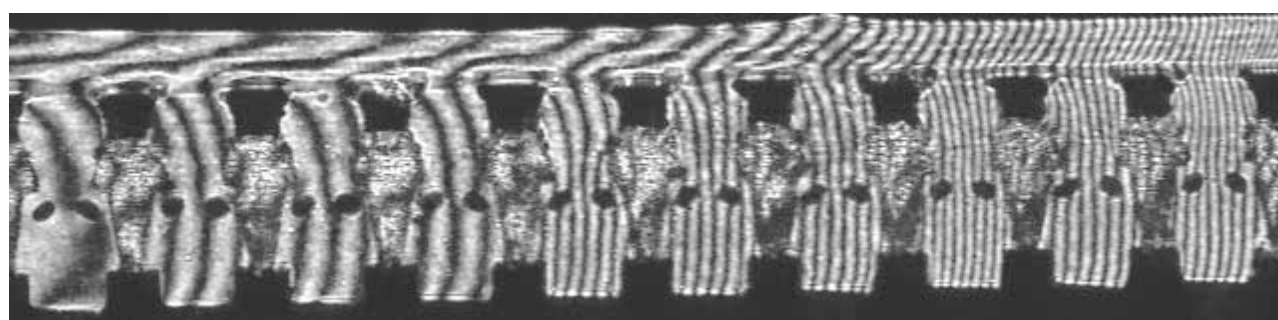

(c)

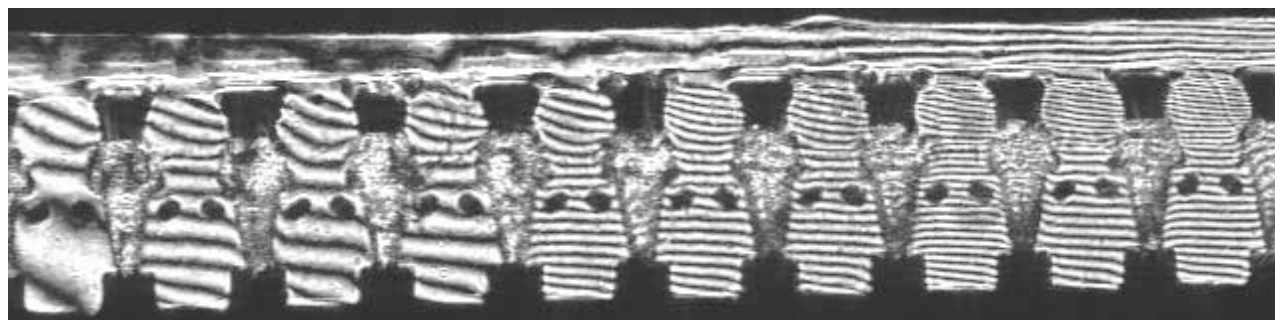

(d)

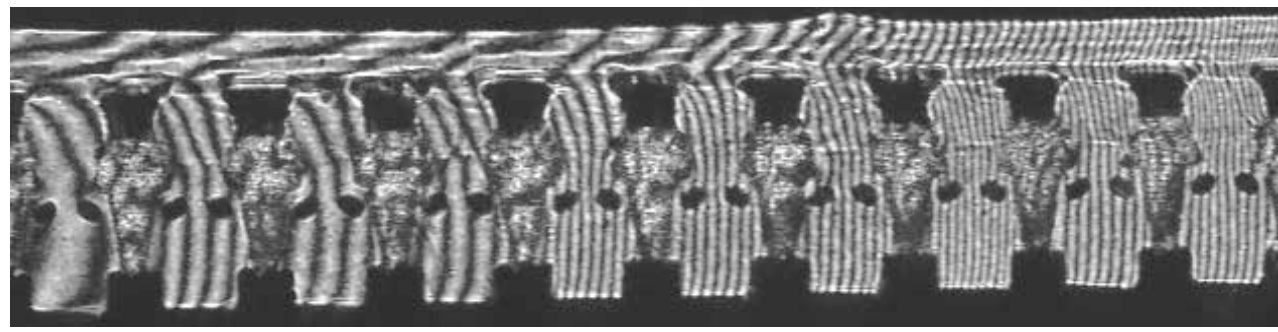

(e)

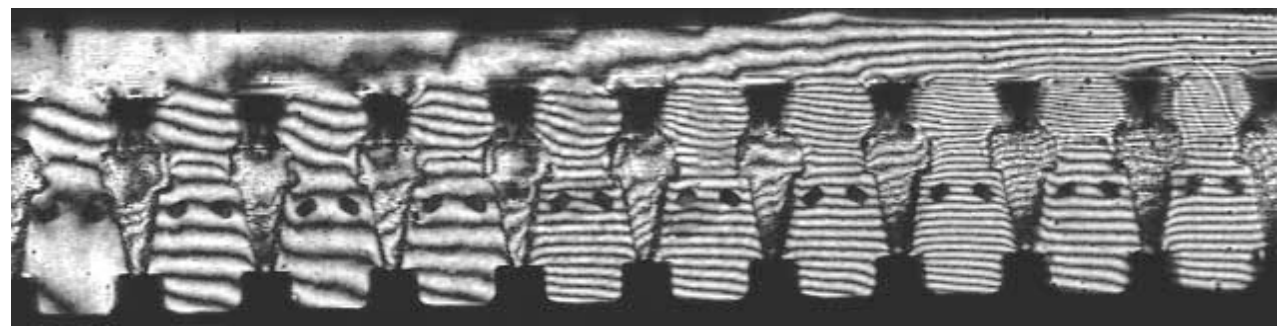

Fig. 11. (a) Initial $U$-field of isothermal temperature at $100^{\circ} \mathrm{C}$, (b) initial $V$-field of isothermal temperature at $100^{\circ} \mathrm{C}$, (c). $U$-field after 42 min dynamic cycling of $50 \mathrm{~Hz}$ at $100^{\circ} \mathrm{C}$, (d) $V$-field after 42 min dynamic cycling of $50 \mathrm{~Hz}$ at $100^{\circ} \mathrm{C}$, (e) $U$-field after 42 min dynamic cycling of $500 \mathrm{~Hz}$ at $100^{\circ} \mathrm{C}$, (f) $V$-field after 42 min dynamic cycling of $500 \mathrm{~Hz}$ at $100^{\circ} \mathrm{C}$, (g) $U$-field after 42 min dynamic cycling of 1000 $\mathrm{Hz}$ at $100^{\circ} \mathrm{C}$, (h) $V$-field after $42 \mathrm{~min}$ dynamic cycling of $1000 \mathrm{~Hz}$ at $100^{\circ} \mathrm{C}$, (i) $U$-field after 42 min dynamic cycling of $700 \mathrm{~Hz}$ at $100^{\circ} \mathrm{C}$ and (j) $V$-field after 42 min dynamic cycling of $700 \mathrm{~Hz}$ at $100^{\circ} \mathrm{C}$. 


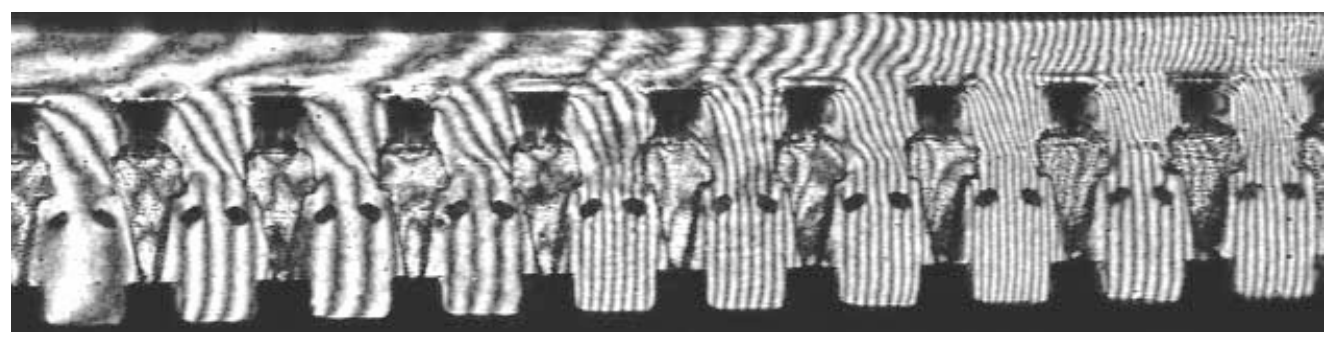

(g)

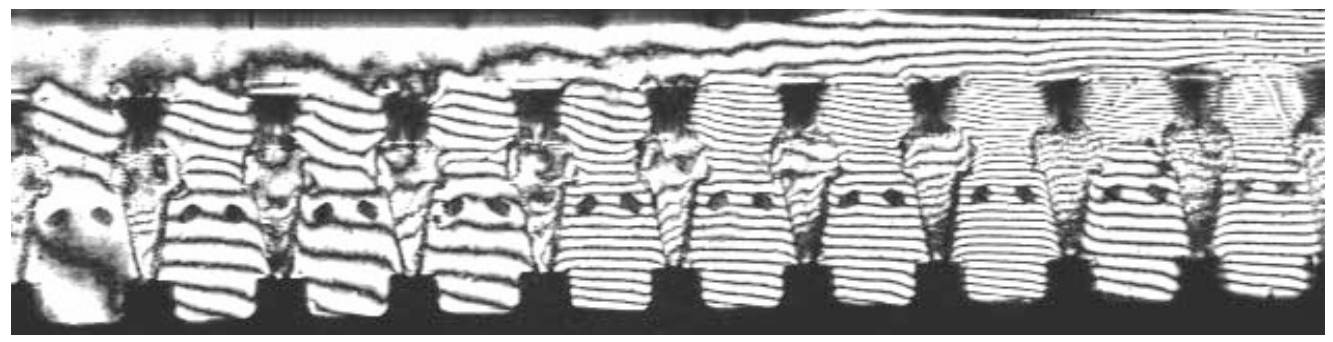

(h)

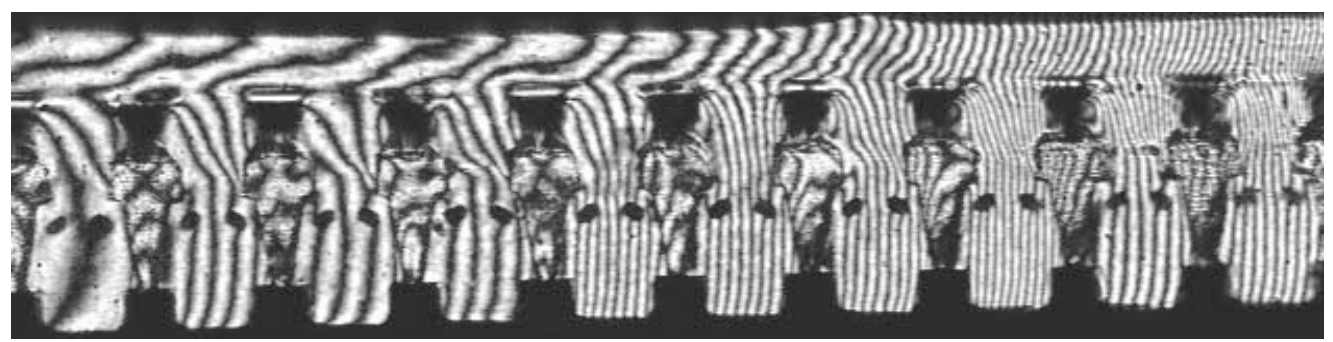

(i)
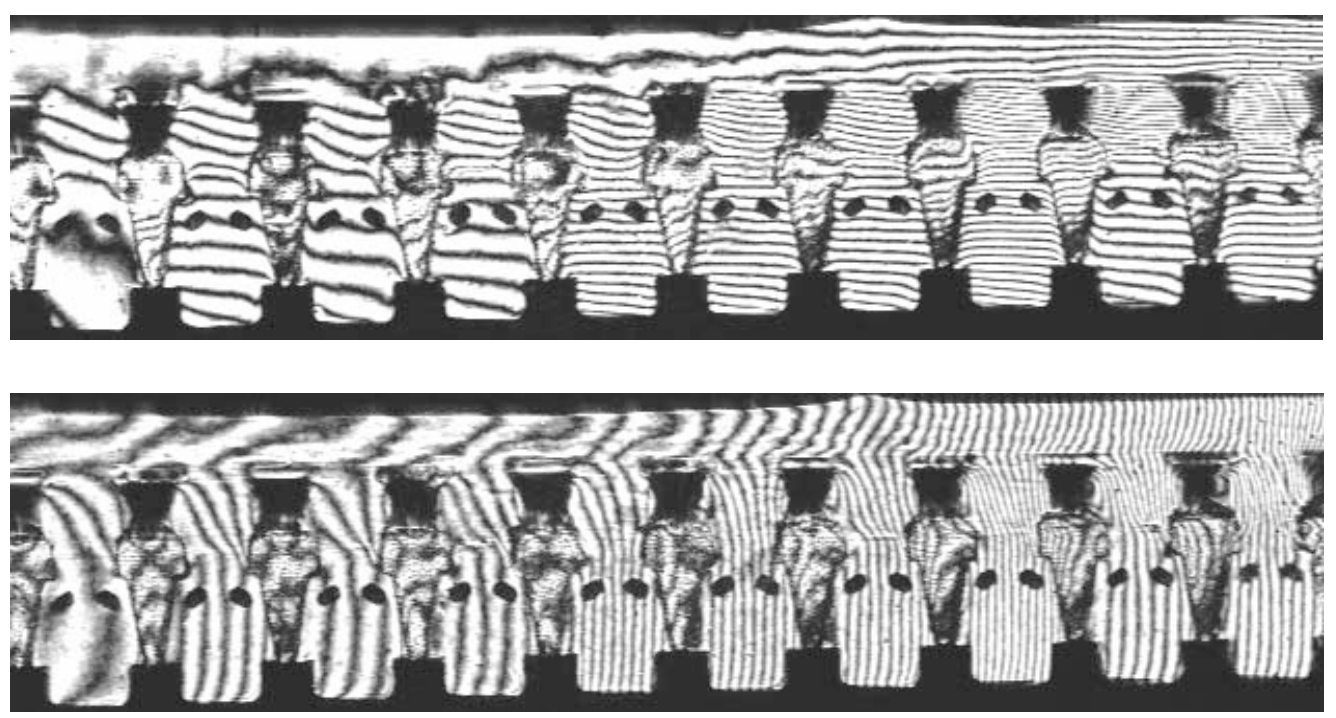

Fig. 11. Continued. 


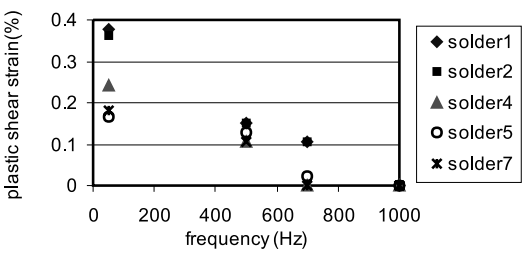

Fig. 12. Plastic strain vs. frequency.

frequency, solder material responds plastically at high temperature while it responds elastically at lower temperature. Therefore, vibration at high homologous temperature is very harmful to solder joint fatigue life.

Essentially the solder behaves elastically for higher frequencies and inelastically for lower frequencies. This observation is consistent with the experience reported by Steinberg (1988) "Solder joints that are exposed to low-rate alternating stresses will fail more quickly than solder joints that are exposed to high-rate alternating stress". Basaran and Chasaroy (1998) have shown that this is due to the fact that at lower frequencies the period of the loading is higher. The time dependent inelastic deformations are directly related to the period of the load. When the load has a longer period the material has more time to creep. Consequently for vibrations with small frequencies creep dominates the response.

\section{Conclusion}

Both shock and harmonic vibration tests were conducted at room temperature and at elevated temperature with different acceleration and frequency levels. Testing is performed on real life electronic packages that provide true perspective of reliability and failure analysis of BGA solder joints. MI is a very useful and highly sensitive method in measuring submicron deformation and providing a whole field distribution of deformation.

It can be summarized from the test data that solder joints respond elastically at room temperature under either shock or sine vibration loading.
Inelastic deformation may be still accumulating albeit very slowly. At elevated temperature, both shock and vibration induce significant inelastic shear deformation in solder joints, thus shorten the fatigue life of solder joints. The solder joints suffer more severe damage at lower vibration frequencies than at higher ones. At $100^{\circ} \mathrm{C}$, the test data show that dynamic loading with frequencies higher than $1000 \mathrm{~Hz}$ have little effect to solder inelastic response.

Thus it can be concluded that contrary to popular belief, the solder alloy does not remain in the elastic region. With a low melting point $\left(183^{\circ} \mathrm{C}\right)$ and high viscoplastic characteristics, eutectic solder alloy shows creep behavior during dynamic loading process which should not be underestimated in solder joint fatigue life prediction.

\section{Acknowledgements}

This research project is sponsored by the Department of Defense Office of Naval Research Young Investigator Award to Dr. C. Basaran. Helpful discussions with Dr. Roshdy Barsoum, Director of Solid Mechanics Program at ONR are gratefully acknowledged.

\section{References}

Basaran, C., Chadaroy, R., 1998. Mechanics of Pb40/Sn60 near eutectic solder alloys subjected to vibrations. Applied Mathematical Modeling 22, 601-627.

Basaran, C., Chadaroy, R., 1999a. Nonlinear dynamic analysis of surface mount interconnects: Part I. Theory. ASME Journal of Electronic Packaging 121 (1), 8-12.

Basaran, C., Chadaroy, R., 1999b. Nonlinear dynamic analysis of surface mount interconnects: Part II. Applications. ASME Journal of Electronic Packaging 121 (1), 12-18.

Basaran, C., Zhao, Y., 1999. Closed form vs. finite element analysis of laminated stacks. International Journal of Finite Elements in Analysis and Design, accepted for publication.

Chandaroy, R., 1998. Damage mechanics of microelectronic packaging under combined dynamic and thermal loading. Ph.D. dissertation, SUNY at Buffalo.

Ham, S.-J., Lee, S.-B., 1996. Experimental study for reliability of electronic packaging under vibration. Experimental Mechanics 36 (4), 339-344. 
Lau, J.H., Rice, D.W., 1985. Solder joint fatigue in surface mount technology: state of the art. Solid State Technology, 91-104.

Lau, J., Powers-Maloney, L.M., Baker, J.R., Rice, D., Shaw, B., 1990. Solder joint reliability of fine pitch surface mount technology assemblies. IEEE Transactions on CHMT 13 (3), 534-544.

Liguore, S., Followell, D., 1995. Vibration fatigue of surface mount technology (SMT) solder joints. In: 1995 Proceedings Annual Reliability and Maintainability Symposium, pp. 18-26.

Markstein, H.W., 1987. Designing electronics for high vibration and shock. Electronic Packaging and Production, 40-43.

Post, D., Han, B., Ifju, P., 1994. High Sensitivity Moiré. Springer, New York.
Sidharth, Barker, D.B., 1995. Vibration induced fatigue life estimation of corner leads of peripheral leaded components. In: 1995 ASME International Mechanical Engineering Congress and Exposure.

Steinberg, D.S., 1988. Vibration Analysis for Electronic Equipment, Wiley, New York.

Wong, T.-L., Stevens, K.K., Wang, G., 1991. Experimental model analysis and dynamic response prediction of PC boards with surface mount electronic components. Journal of Electronic Packaging 113, 244-249.

Zhao, Y., Basaran, C., Cartwright, A., Dishongh, T., 1999. An experimental observation of thermomechanical behavior of BGA solder joints by Moiré Interferometry. Journal of Mechanical Behavior of Materials, 10 (3), 135-146. 